\title{
IMPACT OF COVID-19: EVIDENCE FROM MALAYSIAN STOCK MARKET
}

\author{
Kelvin Yong-Ming Lee* \\ Universiti Malaysia Sarawak \\ Mohamad Jais \\ Universiti Malaysia Sarawak \\ Chia-Wen Chan \\ Asia Metropolitan University
}

\begin{abstract}
Since the first case was reported at the end of 2019, COVID-19 has spread throughout the world resulting in more than 2 million confirmed cases. The World Health Organization (WHO) also declared the COVID-19 disease as pandemic on 11 March 2020. The COVID-19 pandemic has also affected the global financial market, which includes Malaysia. This study aims to investigate the impact of the COVID-19 outbreak on the Malaysian stock market. The dependent variables used in this study were the Kuala Lumpur Composite Index (KLCI) and 13 other sectorial indices. The independent variables were (i) the number of COVID-19 cases in Malaysia, China, and USA; (ii) the number of deaths due to COVID-19 in Malaysia, China, and USA; (iii) the volatility index, and (iv) the Brent oil price. The sample period of this study covered from $31^{\text {st }}$ December 2019 to $18^{\text {th }}$ April 2020. The findings showed that higher numbers of COVID-19 cases in Malaysia tended to adversely affect the performance of the KLCI index and all sectorial indices, except for the Real Estate Investment Fund (REIT) index. The results also showed that the Brent oil price and the volatility index tended to affect the Malaysian stock market performance. The results of this study can help investors understand the impact of COVID-19 on different sectors in Malaysia.
\end{abstract}

Keywords: COVID-19; Stock market; Sectorial indices.

\section{INTRODUCTION}

The Coronavirus (COVID-19) outbreak started in the city of Wuhan, in the Hubei region of China in December 2019. Then, the virus spread to other cities and countries in less than a month. The World Health Organization (WHO) released the first coronavirus monitoring report on 21 January 2020. Two days later, China imposed the lockdown in Wuhan, Hubei. The COVID-19 outbreak in China also heavily affected its tourism industry and other linked industries, which caused an estimated loss of 5,000 Chinese yuan revenue (Hamid, 2020). In addition, the consumer or retail

\footnotetext{
* Corresponding Author: Kelvin Lee Yong Ming, Faculty of Economics and Business, Universiti Malaysia Sarawak, Taman Uni Central, 94300 Kota Samarahan, Sarawak, Malaysia; Email: kelvinklym910104@gmail.com; Tel: +(60)12-7138187.
} 
sector in China is expected to be adversely affected since consumers are restricted from going out (Estrada et al., 2020).

As shown in Figure 1, the number of COVID-19 cases increased rapidly in China in February 2020 (yellow-colored area). The reproduction number of the COVID-19 virus was also found to be higher (fall into the range of 2 and 6) than that of SARS (Liu, Gayle, Wilder-Smith, \& Rocklov, 2020). This simply means that an infected person may infect 2 to 6 other people. In March 2020, COVID-19 started to spread to other countries (refer to Figure 2), although China had successfully slowed the rate of spread (refer to the green-colored area of Figure 1). On 11 March 2020, the president of World Health Organization (WHO), Dr. Kluge announced that the COVID-19 outbreak was a pandemic. As of 16 April 2020, COVID-19 has affected the health of more than 2 million people from more than 200 countries or regions in the world. In addition, more than 145,574 people have died due to the deadly COVID-19 diseases (Worldmeter, 2020).

Due to the COVID-19 pandemic, many countries closed their border to stop visitors to their countries (The Economist, 2020). Relatedly, global passenger revenue is estimated to fall by $55 \%$ (or about US $\$ 314$ billion) in 2020 (IATA, 2020). The movement restriction and closure of business activities also caused the global petrol demand to reduce by an estimated 20 million barrels per day (Brower \& Sheppard, 2020). In addition, Ozili (2020) pointed out that COVID-19 pandemic has affected the stock market in two ways. First, the pandemic forced the shutdown of business and corporate activities, then affected the financial market. Second, uncertainty about the COVID-19 cases also influenced investors' investment decisions, which then caused greater volatility in the stock market. Consequently, many companies experienced liquidity problems regardless of their size (Tashanova, Sekerbay, Chen, Luo, Zhao \& Zhang, 2020). Thus, three organizations-World Bank, Asian Development Bank, and International Monetary Fund - set aside a total of US $\$ 68.5$ billion to help the affected countries (Khan \& Khan, 2020).

Figure 1: COVID-19 Cases in China (1 Jan 2020 - 31 Mar 2020)

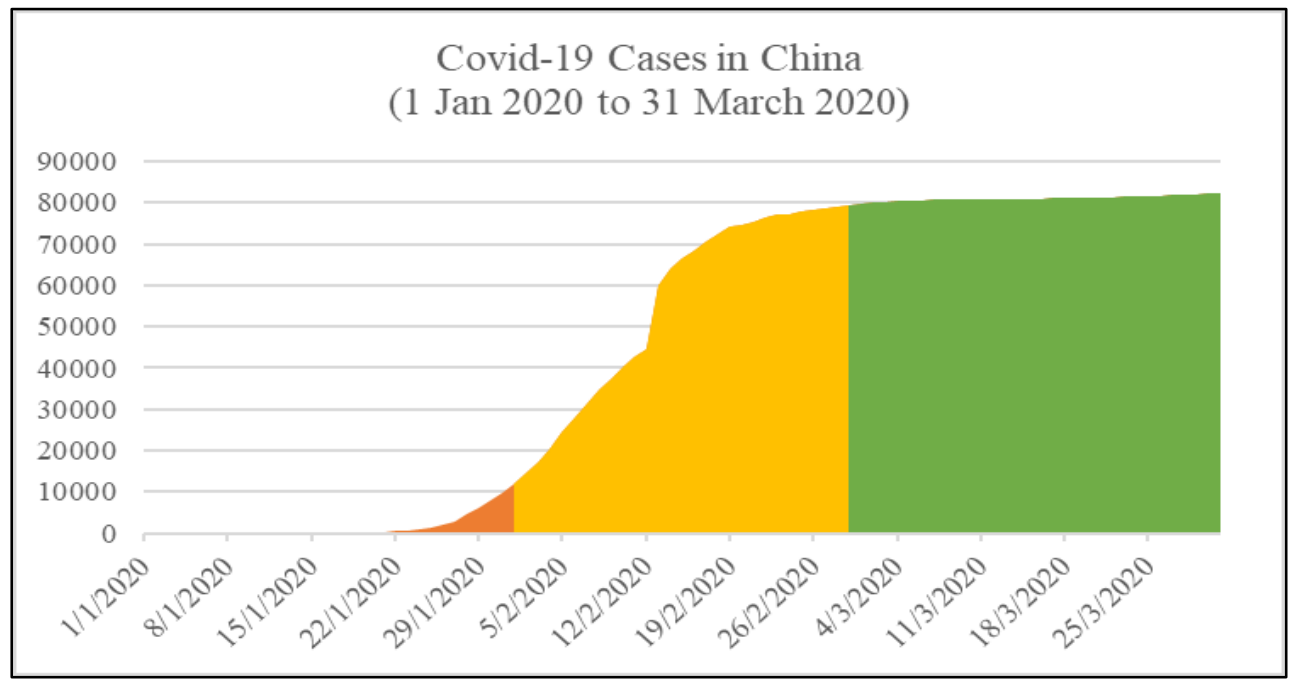

Source: Worldometer.com 
Figure 2: COVID-19 Cases Outside China (1 Jan 2020 - 16 Mar 2020)

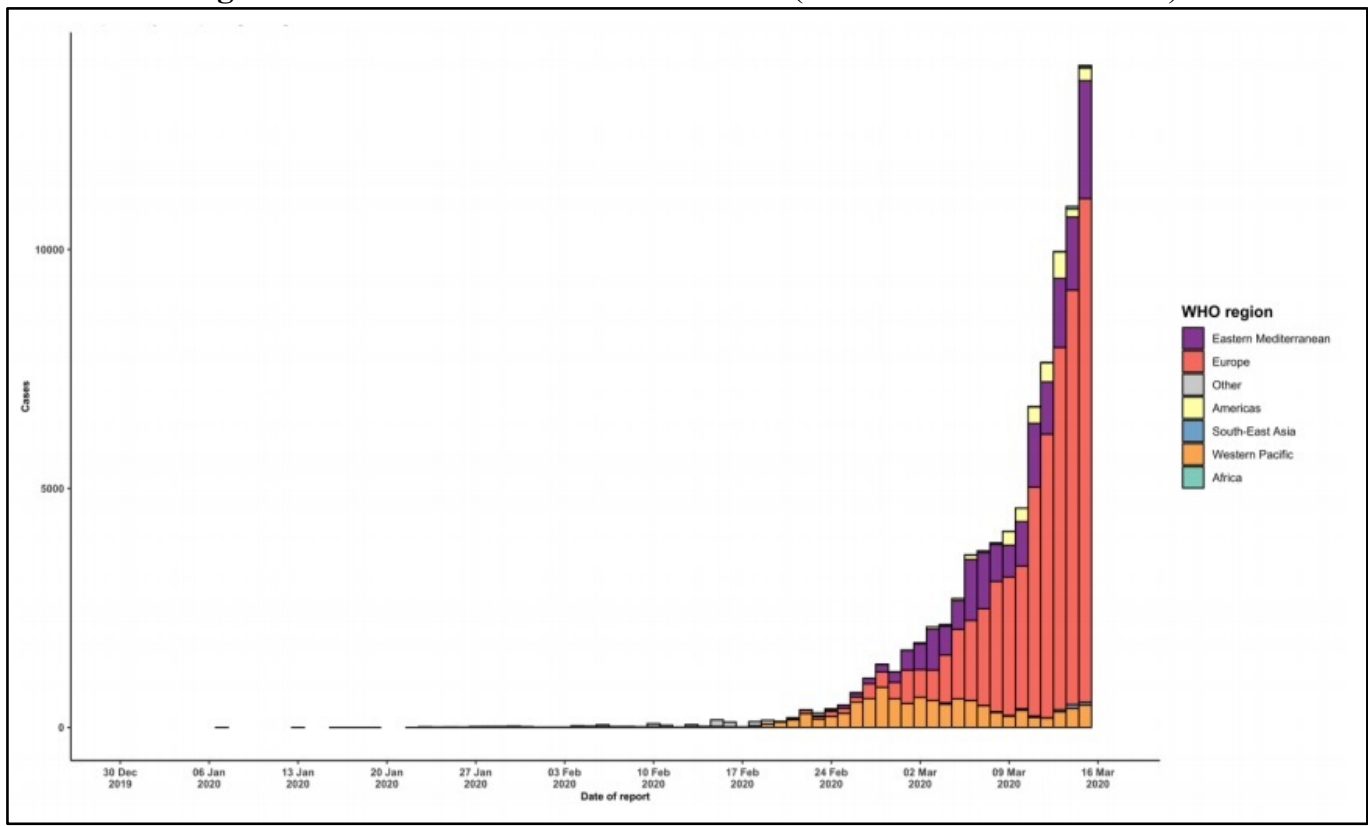

Source: World Health Organization (WHO)

In Malaysia, the first COVID-19 cases were recorded on 25 January 2020 and increased to 25 cases by the end of February 2020 (refer to Figure 3). As depicted in Figure 4, the number of cases increased dramatically from 25 cases on 1 March 2020 to 2,626 cases on 31 March 2020. Due to the outbreak, the government of Malaysia announced a movement control order (MCO) effective from 18 March 2020 to 31 March 2020. In light of the uptrend for the number of COVID-19 cases, the government announced the second phase of MCO effective from 1 April 2020 to 14 April 2020. The lockdown in China has affected the supply and demand curve throughout the world and heavily impacted the Malaysian economic system. The tourism-related industry was the first affected industry because there were more than 10 million visitors from China and Singapore to Malaysia in first three quarters of 2019 (Azman, 2020). Further, more than 170,000 hotel room bookings, value at RM 68 million were cancelled-majority of which came from China (Malaysia Association of Hotel, 2020). The COVID-19 outbreak also hit the airline industry, and the number of passengers fell by 25.49 million persons. This also caused the airline industry to experience a loss in revenue of more than US $\$ 3.3$ billion and influenced about 169,700 related jobs (IATA, 2020). 
Figure 3: COVID-19 Cases in Malaysia (25 Jan 2020 - 29 Feb 2020)

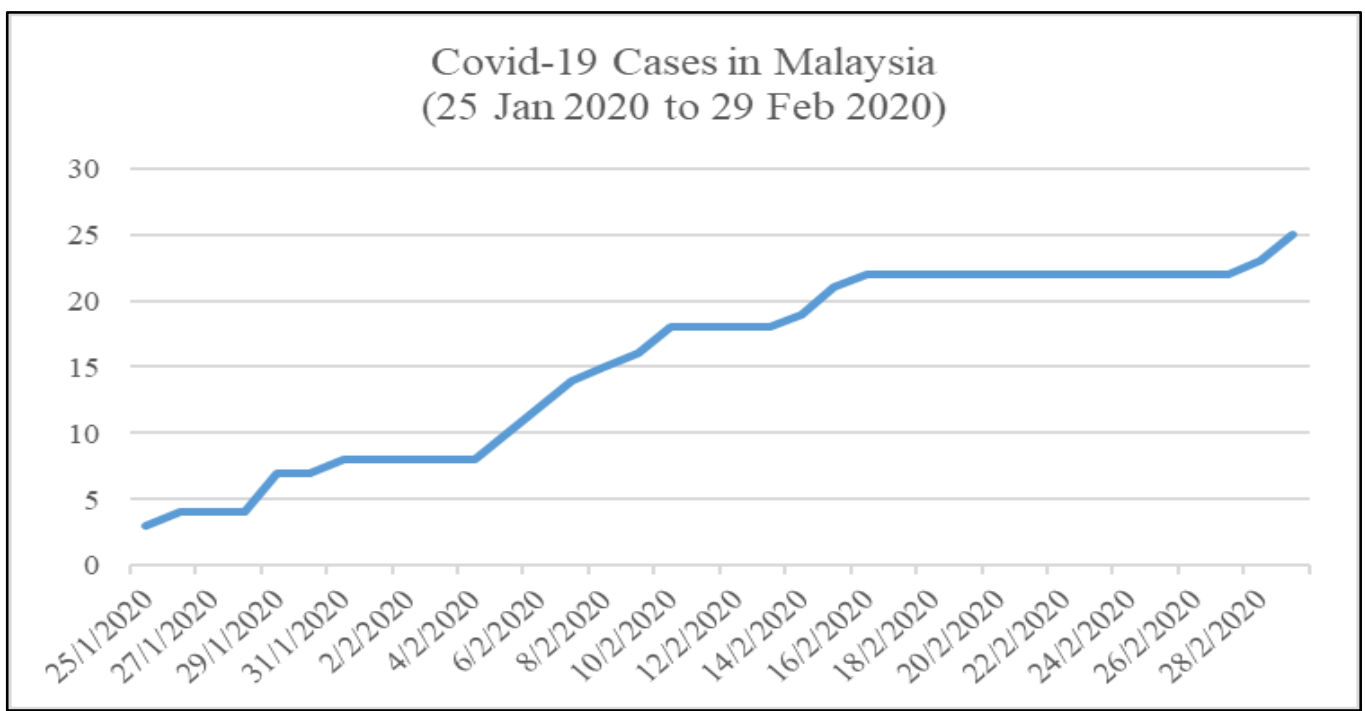

Source: World Health Organization (WHO)

Figure 4: Covid-19 Cases in Malaysia (1 Mar 2020 - 31 Mar 2020)

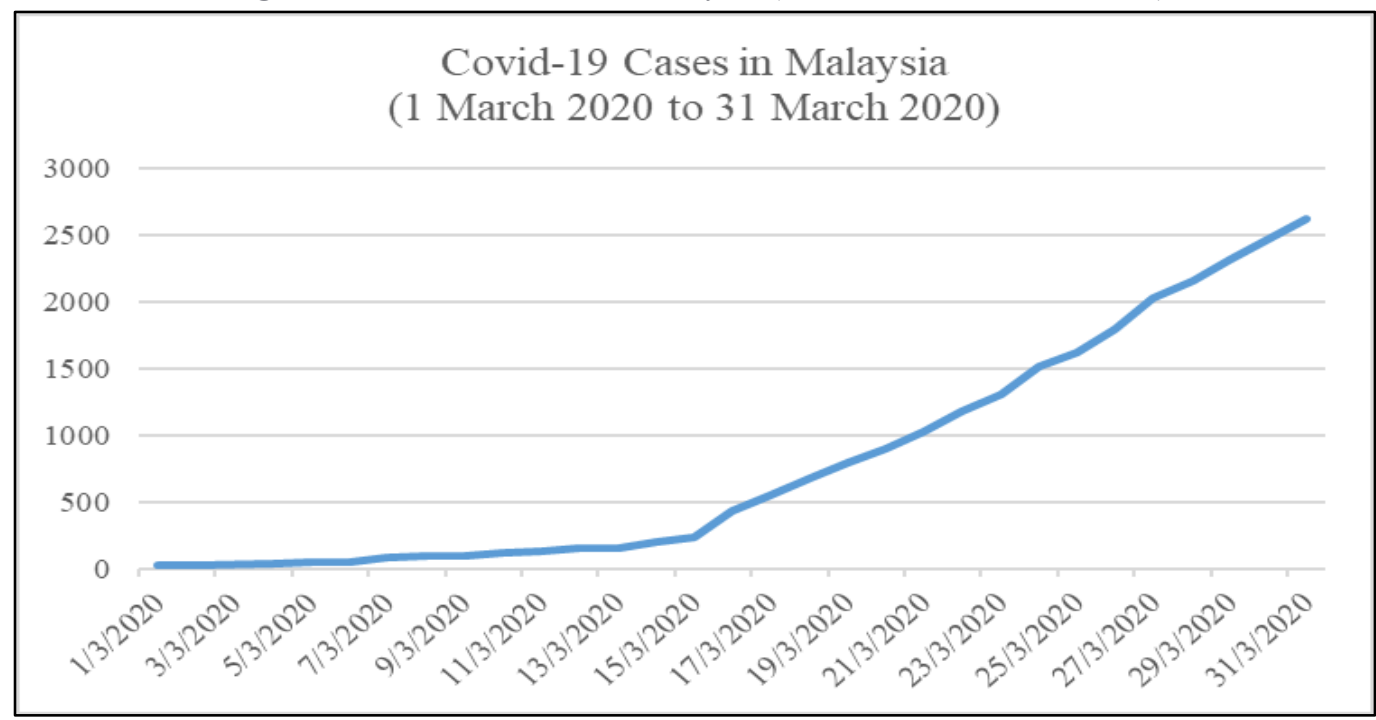

Source: World Health Organization (WHO)

On 27 March 2020, the government of Malaysia announced economic stimulus packages, namely Prihatin Packages, valued at RM 250 billion to ease the financial burden of the citizens. Ten days later, Malaysia also announced additional economic stimulus packages-Prihatin Plus valued at RM 10 billion - to ease the financial burden of Small and Medium Enterprise (SME). This may 
help the 907,065 SMEs in Malaysia that contributed nearly 40\% of the Gross Domestic Product (GDP) of Malaysia. Among the listed companies, major shareholders also disposed of their shares in the first few trading days of MCO due to the uncertainty caused by the COVID-19 and MCO (Star Media, 2020). Figure 5 shows the movement of the Kuala Lumpur Composite Index (KLCI) over the period from 31 December 2019 to 17 April 2020. Generally, the KLCI has experienced a downtrend since the beginning of January 2020, and recorded a lowest point of 1,219.71 on 19 March 2020 (second day of MCO). Thereafter, KLCI slowly came back to the level of 1,400.

Figure 5: Movement of KLCI (31 Dec 2019 - 17 Apr 2020)

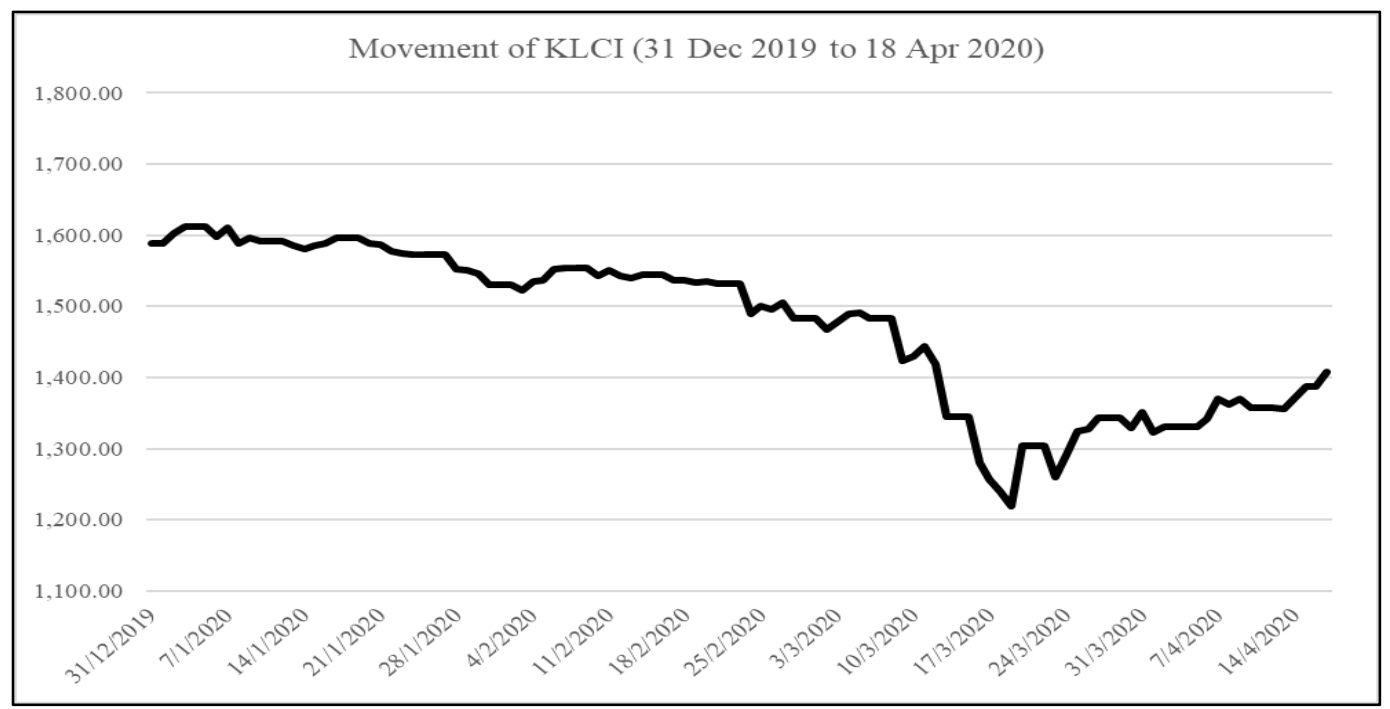

Source: Investing.com

Currently, the main gap in the existing research is the lack of comprehensive view on the impact of COVID-19 toward all the sectors in a particular market. It is also worth noting that the COVID19 outbreak affects almost all sectors. Thus, this study addresses the knowledge gap by including all the sectors in Malaysia as the sample of study. The main aim of this study is to investigate how the COVID-19 outbreak affected all the sectors in the Malaysian stock market. In addition, this study investigates the impact of two external factors: Brent oil price and financial market volatility on the Malaysian stock market. Unlike previous studies, the results of this study are also expected to help investors to understand the impact of COVID-19 on the performance of different sectors in Malaysia. Meanwhile, by providing empirical evidence, the findings of this study could also be used as guidelines for future research. The remainder of this study is organized and structured as follows: The next section reviews the relevant research related to the impacts of SARS and COVID-19. Section 3 discusses the data and methodology used in this study. Section 4 presents the interpretation and discussion of the study's empirical results. Finally, the last section includes the conclusion and recommendations. 


\section{LITERATURE REVIEW}

This section reviews the related literature that discussed the impacts of the SARS outbreak and COVID-19 outbreak.

\subsection{Impact of Severe Acute Respiratory Syndrome (SARS)}

After the first case was reported in China's Guangdong Province in November 2002, SARS disease spread rapidly to 29 countries and three regions (Wang \& Jolly, 2007). According to the WHO, there were 8,422 cases and 916 deaths due to SARS. Meanwhile, SARS also hit the global economy with the estimated loss from US $\$ 30$ to $\$ 100$ billion. Specifically, the disease caused China to face a total loss of US \$25.3 billion in 2003 (Hai, Zhao, Wang, \& Hou, 2004; Smith, 2006).

Hong Kong was one of countries severely affected by the outbreak of SARS, however, there was no heavy impact found in the stock market (Siu and Wong, 2004). Additionally, Wong (2008) examined the reaction of the housing market to the SARS outbreak and revealed that the price of estates started to decline by 1.6 percent when the SARS epidemic began, but estate prices in Hong Kong did not show any overreaction to the SARS outbreak. Wong (2008) suggested that Hong Kong households adopted the strategy of "wait and see" during the SARS epidemic.

In the context of Taiwan, Chen, Chen, Tang, and Huang (2009) examined the impacts of the SARS outbreak on the stock market during the outbreak period in 2003. Specifically, they only studied the impacts on particular industries including airlines, tourism, retail stores, and biotech sectors. Data of 32 specific firms was gathered and by employing the event study approach to analyze the data, their results showed that the SARS outbreak negatively impacted airlines and the tourism and retail store sectors. However, they found that the SARS outbreak tended to enhance the performance of biotechnology companies. They realized that fund managers and investors actively traded biotechnology stocks to construct a better risk-return trade off portfolio during the SARS outbreak in Taiwan.

Similar to Chen et al. (2009), Beutels, Jia, Zhou, Smith, Cao and Vias (2009) examined the impact of the SARS outbreak on several sectors in Beijing, China. The sectors included transportation, airlines, and tourism. In addition, they also studied the economic impacts of the SARS outbreak. The results showed that SARS affected the transportation, airline, and tourism sectors. Specifically, Beutels et al. (2019) reported that the tourism sector faced losses of $\$ 1.4$ billion due to SARS, which is equivalent to 300 times to the cost of treatment.

Recently, Chen, Lee, Lin, and Chen (2018) employed the advanced smooth time-varying cointegration model to investigate the existence of a time-varying cointegration relation between China and four Asian markets-Hong Kong, Taiwan, Singapore, and Japan. The period of the study ranged from 1998 to 2008, which covered the 5 years before and after the SARS outbreak. Their results showed that the SARS outbreak adversely affected the long-term relationship between China and the four markets. These results also suggested the China investors used international portfolio diversification to enhance their portfolio returns, especially during the economic crisis period. Finally, Chen et al. (2018) recommended portfolio diversification within the five countries included in their study. 
Qiu, Chu, Mao, and Wu (2018) conducted a study to compare the social and economic impacts of SARS and H7N9 in China. They found that both disease outbreaks brought negative impacts to China's stock market performance. After the experience of the SARS outbreak, China was better prepared in facing the H7N9 outbreak and made information available to the rest of the world. Hence, the social and economic impacts of the H7N9 outbreak were found to be lower than the SARS outbreak.

\subsection{Impact of COVID-19}

The number of COVID-19 cases has grown rapidly in the rest of the world. To stop the spread of the disease, many countries restrict their citizens' travel and closed down their business activities, and major events, including schooling (Toda, 2020). In addition, the COVID-19 outbreak has affected the global supply chain and disrupted the global economic system (OECD, 2020). Baldwin and Mauro (2020) stated that the economic system was experiencing three shocks. First, they stated that household spending shall be reduced due to the unpaid holiday or experience during COVID19 pandemic period. Second, they mentioned that lower aggregate demand also tends to disrupt the import and export activities for affected countries. Third, the manufacturing sector was also affected by the COVID-19 pandemic since the people and businesses shall apply the "wait-andsee" approach and postpone their orders from manufacturer.

In the United States, Yilmazkuday (2020) examined the impacts of COVID-19 on the S\&P 500 index by using the daily data covered from 31 December 2019 to the day before the pandemic declaration. Using the Structural Vector Autoregression model, the researcher estimated that one global COVID-19 death shall reduce the S\&P index by $0.02 \%$ daily, $0.06 \%$ weekly, and $0.08 \%$ monthly. On 15 March 2020, the U.S. Federal Reserve and the Bank of England lowered their rate to the minimal level that ranged between $0-0.25 \%$ (Fernandes, 2020). A few days later, the European Central Bank (ECB) increased the amount available for the quantitative easing program by having a negative rate. Governments throughout the world also came out with different policies to ease the liquidity problems faced by small and medium enterprise (SMEs) and provide financial support to needy households. The GDP of the affected countries is estimated to fall up to $10 \%$ (Fernandes, 2020).

Zeren and Hizarci (2020) examined the impacts of COVID-19 on several stock markets by using the daily data from January 2020 to March 2020. Three different datasets were included in this study, which included (i) the total numbers of deaths caused by COVID-19, (ii) total COVID-19 cases, and (iii) stock indices. Specifically, the total number of COVID-19 cases was found to have a cointegration relationship with the stock markets in China, Korea, and Spain. Surprisingly, there was no relationship found between the COVID cases and the performance of the stock markets in France, Germany, and Italy. They also mentioned that the behavior of investors in the French, German, and Italian stock markets was not affected by the increase in the COVID-19 cases.

Zeren and Hizarci (2020) and Yan, Andy, Logan, and Zhang (2020) also suggested that investors switch their investments to the gold market during this pandemic. Yan et al. (2020) also recommended that investors short their investments in three other sectors, which included travel-, technology-, and entertainment-related stocks. On the other hand, Tashanova et al. (2020) recommended that investors invest in several defensive industries in this critical period, namely, online entertainment or education, food and healthcare industry. Li, Zhang, Zhang, and Zhang 
(2020) also recommended investing in the healthcare sector and avoiding the luxury sector because they found a high fluctuation in the share price of luxury sector companies. Nia (2020) reported that the Indonesian stock market was experiencing a significant downtrend, however, she mentioned that short-term traders may take the opportunity to target undervalued shares during this outbreak period. She also recommended that Indonesian investors invest in banking and consumer industries.

A recent study carried out by Albulescu (2020) examined the impacts of COVID-19 on the financial volatility of China's stock market for the 40 days after the international monitoring of COVID-19 began. The researcher measured COVID-19 from two aspects, the reported COVID19 cases and death ratio. The results showed that the number of COVID-19 cases reported in China had a negative relationship with financial market volatility. However, the number of COVID-19 cases reported outside China tended to increase the financial market volatility. Moreover, the results showed that a higher death ratio, regardless of inside or outside China, tended to increase financial market volatility. Notably, the death ratio outside China had a bigger impact, in which a $1 \%$ increase in death ratio tended to increase financial market volatility by $11 \%$.

Zhou, Wu, Liu, Gao, and Gao (2020) examined the economic impacts of COVID-19 on several industries. They revealed that the number of COVID-19 infection cases in China positively related with performance of healthcare industry and negatively related with other industries, such as transportation, construction, and tourism. On the other hand, Estrada, Park, and Lee (2020) examined the impacts of COVID-19 on four industries, which included tourism, airlines, trading, and utilities, in China. They revealed that all sectors were adversely affected by the COVID-19 outbreak, except for the utilities industry. They further explained that the lockdown and medical services increased electricity consumption and thus enhanced the performance of electricity sectorial index.

Due to the COVID-19 outbreak, the Indian government also predicted a fall in government revenue for at least half year (Rani, 2020). However, performance of the pharmaceutical industry tended to move in a different direction during this critical period. Aravind and Manojkrishnan (2020) examined the impacts of the COVID-19 outbreak on the pharmaceutical industry in India. The top 10 companies from the pharmaceutical industry served as the sample of the study. However, the sample period used in this study only covered the period before the WHO declared the pandemic. This study revealed that the branded pharmaceutical companies sustained in the crisis period. But, the production level of the Indian pharmaceutical companies was reduced because the supply chain for the ingredients was affected. The researchers also explained the break in the supply chain because the ingredients of the Indian pharmaceutical companies primarily come from China.

Watanabe (2020) examined the impacts of the COVID-19 crisis on consumption in Japan. This study also compared the impacts of the COVID-19 crisis with the impacts of the 2011 Tohoku Earthquake. He revealed some recurring consequences after both. Similarly, the growth in sales of retail were reduced by $20 \%$ and the types of items purchased by the consumers were quite similar. However, the inflation rate for the post COVID-19 outbreak was only $0.6 \%$ and it was relatively lower than the one after the earthquake. The researcher explained that the COVID-19 outbreak has affected the demand, instead of the supply of goods or services. Contradictory to the current outbreak, the Tohoku Earthquake affected the supply of goods or services and resulted in higher inflation. 
Sansa (2020) examined the impact of COVID-19 on the stock markets in China and USA by using the daily data of March 2020. The number of confirmed COVID-19 cases was used as the independent variable, and the stock indices were used as the dependent variables. They revealed that there is a positive relationship between the number of COVID-19 cases and the stock indices. Generally, their findings contradict the evidence provided by other studies. This may be due to the short sample period used.

Liu, Manzoor, Wang, Zhang, and Manzoor (2020) examined the impacts of the COVID-19 outbreak on 21 stocks indices by using an event study method. They revealed that investors' pessimistic sentiment led to the fall in the abnormal return of the stock indices. Specifically, they revealed that the abnormal return of Asian stock indices drop more than the other indices during the COVID-19 outbreak. However, they highlighted that Asian stock markets tended to react faster and was able to recover at the later stage of pandemic.

In summary, existing studies only investigated the impact of COVID-19 on major indices of a particular country. Although some studies focused on analyzing some affected sectors, the analysis should be conducted in more comprehensive way. Thus, this study aims to fill in the knowledge gap by investigating the relationship between the COVID-19 outbreak and the performance of all sectors in the Malaysian stock market.

\section{DATA AND METHODOLOGY}

This section discusses the data and methodologies applied in this study. To examine the impact of COVID-19 on the stock market, this study used the daily data of the period from $1^{\text {st }}$ January 2020 to $18^{\text {th }}$ April 2020. The data were collected from various sources. The dependent variable used was stock indices from the Malaysian stock market. This study employed the daily data of the Kuala Lumpur Composite Index (KLCI) and 13 sectorial indices. These sectors included (i) consumer; (ii) construction; (iii) energy; (iv) finance; (v) healthcare; (vi) industrial product; (vii) plantation; (viii) property; (ix) real estate investment trust; (x) technology; (xi) telecommunication and media; (xii) transportation and logistics; and (xiii) utilities. Table 1 shows the number of constituents and market capitalization for the KLCI and sectorial indices.

Table 1: Information of Malaysian Stock Indices

\begin{tabular}{lcc}
\hline \hline \multicolumn{1}{c}{ Indices } & No of Constituents & Market capitalization (RM billion) \\
\hline KLCI & 30 & $1,379.20$ \\
Consumer & 170 & 216.77 \\
Construction & 50 & 24.84 \\
Energy & 26 & 36.58 \\
Finance & 31 & 291.72 \\
Healthcare & 13 & 101.73 \\
Industrial product & 220 & 126.01 \\
Plantation & 43 & 118.66 \\
Property & 96 & 45.67 \\
REIT & 18 & 39.76 \\
Technology & 38 & 27.01 \\
Telecommunication & 16 & 131.28
\end{tabular}




\begin{tabular}{lcc}
\hline \hline \multicolumn{1}{c}{ Indices } & No of Constituents & Market capitalization (RM billion) \\
\hline Transportation & 32 & 61.51 \\
Utilities & 12 & 124.08 \\
\hline \hline
\end{tabular}

Source: Bursa Malaysia Official Website (As of 31 March 2020)

The independent variables used in this study were (i) COVID-19 cases; (ii) COVID-19 death cases; (iii) CBOE VIX index; and (iv) Brent Crude Oil Price. COVID-19-related data were extracted from the database on the official WHO website. Specifically, the number of confirmed cases and number of deaths from three countries were extracted. These three countries were Malaysia, China, and United States. The rationales for using these three countries is as follows: (i) Malaysia was selected because this study intends to investigate the impact of COVID-19 on the Malaysian stock market; (ii) China was selected because China is the top trading partner of Malaysia in terms of foreign investment and number of tourists (Cheng, 2020); (iii) United States was selected because the movement in US market tends to affect the Malaysian market.

The Chicago Board of Option Exchange (CBOE) VIX and Brent Crude Oil Price were also used as independent variables in this study. The CBOE VIX index and Brent Crude Oil Price were downloaded from Investing.com. Several analyses will be conducted after the data collection process. First, descriptive statistics for the Malaysian stock indices will be used to determine the most volatile index. Next, correlation analysis will be used to determine the correlation among the stock indices. In addition, this study applied the Ordinary Least Square regression analysis to investigate the impacts of COVID-19 disease on the Malaysian stock market. The regression models to be tested in this study were:

$$
\begin{aligned}
& S I_{K L C I, t}=\alpha+\beta_{1} M C_{M, t}+\beta_{2} M D_{M, t}+\beta_{3} C C_{C, t}+\beta_{4} C D_{C, t}+\beta_{5} U C_{U, t}+\beta_{6} U D_{U, t}+\beta_{7} B R E N T_{t}+\beta_{8} V I X_{t} \\
& S I_{i, t}=\alpha+\beta_{1} M C_{M, t}+\beta_{2} M D_{M, t}+\beta_{3} C C_{C, t}+\beta_{4} C D_{C, t}+\beta_{5} U C_{U, t}+\beta_{6} U D_{U, t}+\beta_{7} B R E N T_{t}+\beta_{8} V I X_{t} \\
& S I_{K L C I, t}=\alpha+\beta_{1} M C_{M, t-1}+\beta_{2} M D_{M, t-1}+\beta_{3} C C_{C, t-1}+\beta_{4} C D_{C, t-1}+\beta_{5} U C_{U, t-1}+\beta_{6} U D_{U, t-1}+\beta_{7} B R E N T_{t-1} \\
& +\beta_{8} V I X_{t-1} \\
& S I_{i, t}=\alpha+\beta_{1} M C_{M, t-1}+\beta_{2} M D_{M, t-1}+\beta_{3} C C_{C, t-1}+\beta_{4} C D_{C, t-1}+\beta_{5} U C_{U, t-1}+\beta_{6} U D_{U, t-1}+\beta_{7} B R E N T_{t-1}+ \\
& \beta_{8} V I X_{t-1}
\end{aligned}
$$

Where $S I_{K L C I, t}$ is the Kuala Lumpur Composite Index (KLCI) at day $t$; $S I_{i, t}$ is the stock indices from sector $x$ at day $t ; M C_{t}$ is the number of COVID-19 cases in Malaysia at day $t ; M D_{t}$ is the number of death cases in Malaysia at day $t ; C C_{t}$ is the number of COVID-19 cases in China at day $t ; C D_{t}$ is the number of death cases in China at day $t ; U C_{t}$ is the number of COVID-19 cases in United States at day $t: U D_{t}$ is the number of death cases in United States at day $t ; B R E N T_{t}$ is the Brent Oil Price at day $t$; and $V I X_{t}$ is the CBOE Volatility Index at day $t$. The sign of $t-1$ refers to the day before day $t$.

Equation (1) is applicable to Model 1, in which the KLCI is used as the dependent variable. Equation (2) is applicable to Models 2 through 14, in which the sectorial indices are used as the dependent variables. This study also intends to investigate the impact of previous day information to the Malaysian stock indices. Thus, this study tests the relationship between previous day information of eight independent variables with the dependent variable. These eight independent variables were COVID-19 cases from Malaysia, China, and USA, COVID-19 death cases from 
Malaysia, China, and USA, Brent Oil Price and CBOE VIX index. Equation (3) is applicable to Model 1a, in which the lagged independent variables will be used to estimate the KLCI. Equation (4) is applicable to Models $2 \mathrm{a}$ through 14a, in which the lagged independent variables will be used to estimate the sectorial indices.

This study also applies three diagnostic checks for the OLS regression model. These three diagnostic checks are used to test for the multicollinearity, autocorrelation, and heteroscedasticity problem. Specifically, this study applied the Variance of Inflation Factor (VIF) to test for multicollinearity, Durbin Watson statistics to test for auto-correlation, and the Cook and Weisberg test to test for heteroscedasticity. For the multicollinearity test, the VIF greater than 10 indicates a multicollinearity problem (Montgomery, Peck, \& Vining, 2012). For the auto-correlation test, Durbin and Watson (1971) stated that a d-statistic that lies in between the lower bound (dL) and upper bound $(\mathrm{dU})$ of d-statistics indicates an inconclusive result. The d-statistics that are lower than the $\mathrm{dL}$ indicates an autocorrelation, whereas the d-statistics that are greater than $\mathrm{dU}$ indicates no autocorrelation. For the heteroscedasticity test, a $p$-value below 0.05 indicates a heteroscedasticity problem.

\section{RESULTS AND DISCUSSION}

This section discusses the results obtained by analyzing the Kuala Lumpur Composite Index (KLCI) and 13 sectorial indices. Table 2 presents the descriptive statistics of the Malaysian stock indices. Coefficient of variation is calculated to determine the fluctuation of indices. The energy index had the highest $\mathrm{CV}$ of 0.23 , followed by consumer index $(0.16)$ and property index $(0.15)$. This indicated that performance of the energy, consumer, and property sectorial indices highly fluctuated during the sample periods. On the other hand, the healthcare index had the lowest CV of 0.05 , followed by the REIT index (0.06) and utilities sectorial indices (0.07). This indicated that performance of the healthcare, REIT, and utilities sectorial indices were relatively stable during the sample periods.

Table 2: Descriptive Statistics of Stock Indices

\begin{tabular}{lcccccc}
\hline \hline \multicolumn{1}{c}{ Indices } & Mean & Min & Max & Median & SD & CV \\
\hline KLCI & $1,473.23$ & $1,219.72$ & $1,611.38$ & $1,521.95$ & 110.16 & 0.07 \\
Consumer & 181.72 & 121.91 & 212.55 & 196.21 & 30.54 & 0.16 \\
Construction & 588.40 & 466.27 & 658.00 & 621.50 & 62.27 & 0.10 \\
Energy & 996.67 & 513.75 & $1,291.25$ & $1,151.24$ & 265.36 & 0.23 \\
Finance & $13,979.04$ & $10,885.45$ & $15,713.41$ & $14,572.96$ & $1,375.59$ & 0.09 \\
Healthcare & $1,312.19$ & $1,142.40$ & $1,436.24$ & $1,330.95$ & 62.36 & 0.05 \\
Industrial product & 132.43 & 92.52 & 156.40 & 143.31 & 20.48 & 0.14 \\
Plantation & $6,853.14$ & $5,532.03$ & $7,810.20$ & $7,076.82$ & 655.82 & 0.09 \\
Property & 703.24 & 495.19 & 831.67 & 751.18 & 109.90 & 0.15 \\
REIT & 927.13 & 780.16 & 980.10 & 962.81 & 59.82 & 0.06 \\
Technology & 36.17 & 23.81 & 42.32 & 38.44 & 5.16 & 0.13 \\
Telecommunication & 619.44 & 483.54 & 683.35 & 646.86 & 60.25 & 0.09 \\
Transportation & 667.49 & 480.71 & 770.28 & 720.62 & 93.48 & 0.13 \\
Utilities & 931.16 & 752.78 & $1,010.10$ & 955.14 & 69.97 & 0.07 \\
\hline \hline
\end{tabular}

Notes: SD refers to the standard deviation; $\mathrm{CV}$ refers to the coefficient of variation. 
Table 3 presents the result of correlation analysis. Consistently, all the correlation coefficients obtained were positive. The three strongest correlations were found in between the construction and industrial product sectors with a correlation coefficient of 0.996 , followed by the construction and transportation sectors $(0.995)$, and the construction and consumer sectors (0.994). The three weakest correlations were found in between the healthcare and plantation sectors with correlation coefficient of 0.323 , followed by the finance and healthcare sectors $(0.380)$, and the healthcare and property sectors $(0.394)$. Based on Table 2, all the sectorial indices were highly correlated with KLCI, except for healthcare. This indicated that the movement in the healthcare sector was the least likely to be correlated with KLCI.

Table 3: Result of Correlation Analysis

\begin{tabular}{|c|c|c|c|c|c|c|c|}
\hline & (i) & (ii) & (iii) & (iv) & (v) & (vi) & (vii) \\
\hline (i) & 1.000 & & & & & & \\
\hline (ii) & 0.992 & 1.000 & & & & & \\
\hline (iii) & 0.984 & 0.994 & 1.000 & & & & \\
\hline (iv) & 0.979 & 0.991 & 0.989 & 1.000 & & & \\
\hline (v) & 0.989 & 0.985 & 0.969 & 0.971 & 1.000 & & \\
\hline (vi) & 0.422 & 0.430 & 0.475 & 0.422 & 0.380 & 1.000 & \\
\hline (vii) & 0.992 & 0.996 & 0.991 & 0.991 & 0.985 & 0.413 & 1.000 \\
\hline (viii) & 0.984 & 0.976 & 0.966 & 0.968 & 0.962 & 0.323 & 0.977 \\
\hline (ix) & 0.985 & 0.993 & 0.984 & 0.985 & 0.991 & 0.394 & 0.993 \\
\hline (x) & 0.909 & 0.924 & 0.916 & 0.909 & 0.937 & 0.545 & 0.915 \\
\hline (xi) & 0.944 & 0.958 & 0.972 & 0.960 & 0.925 & 0.631 & 0.953 \\
\hline (xii) & 0.984 & 0.993 & 0.991 & 0.984 & 0.979 & 0.462 & 0.990 \\
\hline (xiii) & 0.988 & 0.995 & 0.993 & 0.990 & 0.981 & 0.434 & 0.995 \\
\hline (xiv) & 0.970 & 0.966 & 0.966 & 0.948 & 0.953 & 0.527 & 0.963 \\
\hline & (viii) & (ix) & $(\mathbf{x})$ & (xi) & (xii) & (xiii) & (xiv) \\
\hline
\end{tabular}

(i)

(ii)

(iii)

(iv)

(v)

(vi)

(vii)

(viii)

1.000

(ix)

0.962

1.000

(x)

0.842

0.939

1.000

(xi)

0.904

0.941

0.917

1.000

(xii)

0.959

0.988

0.941

0.964

1.000

(xiii)

0.969

0.991

0.914

0.961

0.989

1.000

0.944

0.955

0.952

0.969

0.961

1.000

Notes: (i) refers to KLCI; (ii) refers to Construction; (iii) refers to Consumer; (iv) refers to Energy; (v) refers to Finance; (vi) Healthcare; (vii) refers to Industrial Product; (viii) refers to Plantation; (ix) Property; (x) refers to REIT; (xi) refers to Technology; (xii) refers to Telecommunication; (xiii) refers to Transportation; and (xiv) refers to Utilities. 
Table 4 presents the results of the regression analysis. The R-square of all models exceeded 0.9 , except for Model 6 and Model 10. This indicated that the variation of the 14 dependent variables was explained by more than $90 \%$ of the independent variables. Based on Table 4 , the number of COVID-19 cases in Malaysia had a significant negative relationship with all the sectorial indices and KLCI, except for the Plantation sector (Model 8). This indicated that the COVID-19 outbreak in Malaysia had significant adverse effect on all the sectors, except for Plantation. However, the performance of the Plantation sector was still negatively related with the number of COVID-19 cases in Malaysia. The results also showed that the number of deaths in Malaysia had a significant positive relationship with only the REIT sector (Model 10). Particularly, a higher number of COVID-19 death cases in Malaysia tended to increase the performance of the REIT sectorial index. This indicated that the REIT sector was a defensive sector during the COVID-19 outbreak.

Noteworthily, the number of COVID-19 cases in China had a significant positive relationship with the performance of the Healthcare sector (Model 6), whereas the number of deaths in China had a significant positive relationship with the performance of the Industrial Product sector (Model 7), Telecommunication sector (Model 12), and Utilities sector (Model 14). This indicated that a worsening COVID-19 outbreak situation in China tended to increase the performance of the Healthcare, Industrial Product, Telecommunication and Utilities sectors in Malaysia. In addition, both the number of COVID-19 cases and number of deaths in USA had a significant positive relationship with the performance of the Industrial Product sector (Model 7) and Utilities sector (Model 14). Under Model 12 and 13, the number of COVID-19 cases in USA had significant negative relationship with the performance of the Telecommunication (Model 12) and Transportation sectors (Model 13). Finally, the number of deaths in USA had a significant positive relationship with performance of the Transportation sector (Model 13). This also indicated that a worsening COVID-19 outbreak situation in USA tended to increase the performance of the Industrial Product and Utilities sectors but lowered the performance of the Telecommunication and Transportation sectors in Malaysia.

Results also showed that the Brent Crude Oil Price had a significant positive relationship with all the sectorial indices and KLCI, except for the Healthcare (Model 6) and Technology sectors (Model 11). Specifically, the Brent Crude Oil Price had a significant negative relationship with the Healthcare sector (Model 6). Under Model 11, the Brent oil price had a positive, but insignificant relationship with the Technology sector. The VIX also had a significant negative relationship with all the sectorial indices and KLCI, except for the REIT sector (Model 10). This indicated that the higher financial market volatility adversely affected the performance of all the sectors in Malaysia, except the REIT.

Based on Table 5, the R-square for Models 1a to 14a ranged from 0.729 to 0.962 , except for Model $6 \mathrm{a}$, where the R-square is only 0.397 . This indicated that the variation of the 13 dependent variables was explained by more than $72.9 \%$ of the lagged independent variables. Based on Table 5 , the lagged number of COVID-19 cases in Malaysia had a negative relationship with almost all the sectorial indices and KLCI, except for the Healthcare sector (Model 6a). This indicated that the number of cases from the previous study also adversely affect KLCI and all the sectorial indices, except for the Plantation sector. On the other hand, the lagged number of deaths in Malaysia had positive, but not significant relationship with the all the sectors and KLCI at $1 \%$ level of significance. This indicated that the death cases from Malaysia from the previous day did not have any significant impact on the sectorial indices and KLCI the next day. 
Table 4: Result of Regression Analysis

\begin{tabular}{|c|c|c|c|c|c|c|c|}
\hline Model & 1 & 2 & 3 & 4 & 5 & 6 & 7 \\
\hline \multirow[t]{2}{*}{ Intercept } & 1362.36 & 510.02 & 162.71 & 624.47 & 11958.33 & 1624.74 & 107.49 \\
\hline & $0.000 *$ & $0.000 *$ & $0.000 *$ & $0.000 *$ & $0.000^{*}$ & $0.000 *$ & $0.000 *$ \\
\hline \multirow[t]{2}{*}{$\mathrm{MC}_{\mathrm{t}}$} & -0.250 & -0.147 & -0.057 & -0.276 & -4.470 & -0.564 & -0.032 \\
\hline & $0.005^{*}$ & $0.000 *$ & $0.003 *$ & $0.051 * * *$ & $0.000 *$ & $0.001 *$ & $0.008^{*}$ \\
\hline \multirow[t]{2}{*}{$\mathrm{MD}_{\mathrm{t}}$} & 1.332 & 1.016 & -0.312 & 0.485 & 31.027 & 1.707 & 0.152 \\
\hline & 0.625 & 0.352 & 0.589 & 0.912 & 0.378 & 0.730 & 0.678 \\
\hline \multirow[t]{2}{*}{$\mathrm{CC}_{\mathrm{t}}$} & -0.001 & 0.001 & 0.001 & 0.003 & -0.030 & 0.005 & -0.001 \\
\hline & 0.375 & 0.762 & 0.130 & 0.244 & 0.156 & $0.074 * * *$ & 0.477 \\
\hline \multirow[t]{2}{*}{$\mathrm{CD}_{\mathrm{t}}$} & 0.017 & 0.013 & 0.006 & 0.031 & 0.092 & 0.046 & 0.006 \\
\hline & 0.405 & 0.118 & 0.155 & 0.333 & 0.722 & 0.210 & $0.034 * *$ \\
\hline \multirow[t]{2}{*}{$\mathrm{UC}_{\mathrm{t}}$} & -0.001 & -0.001 & -0.001 & -0.002 & -0.008 & 0.000 & 0.001 \\
\hline & 0.697 & 0.243 & 0.116 & 0.139 & 0.367 & 0.984 & $0.006^{*}$ \\
\hline \multirow[t]{2}{*}{$\mathrm{UD}_{\mathrm{t}}$} & 0.003 & 0.003 & 0.002 & 0.003 & -0.002 & 0.017 & 0.002 \\
\hline & 0.612 & 0.301 & 0.149 & 0.769 & 0.982 & 0.165 & $0.037 * *$ \\
\hline \multirow[t]{2}{*}{ Brent $t_{t}$} & 3.807 & 2.349 & 0.871 & 10.672 & 55.023 & -4.256 & 0.766 \\
\hline & $0.000 *$ & $0.000 *$ & $0.000 *$ & $0.000 *$ & $0.000 *$ & $0.002 *$ & $0.000 *$ \\
\hline \multirow[t]{2}{*}{$\mathrm{VIX}_{\mathrm{t}}$} & -1.881 & -0.875 & -0.618 & -3.843 & -11.559 & -2.895 & -0.301 \\
\hline & $0.000 *$ & $0.000 *$ & $0.000 *$ & $0.000 *$ & $0.066^{* * *}$ & $0.001 *$ & $0.000 *$ \\
\hline R-Square & 0.954 & 0.977 & 0.973 & 0.980 & 0.951 & 0.527 & 0.976 \\
\hline VIF & 8.410 & 8.410 & 8.410 & 8.410 & 8.410 & 8.410 & 8.410 \\
\hline Durbin Watson & 0.216 & 0.183 & 0.202 & 0.181 & 0.226 & 0.204 & 0.196 \\
\hline \multirow[t]{2}{*}{ Cook-Weisberg } & 8.570 & 7.000 & 5.930 & 5.780 & 6.560 & 0.260 & 7.120 \\
\hline & $0.003 *$ & $0.008^{*}$ & $0.015^{* *}$ & $0.016^{* *}$ & $0.010^{* *}$ & 0.613 & $0.008^{* * *}$ \\
\hline Model & 8 & 9 & 10 & 11 & 12 & 13 & 14 \\
\hline \multirow[t]{2}{*}{ Intercept } & 5720.466 & 494.864 & 836.634 & 41.752 & 558.430 & 584.050 & 809.318 \\
\hline & $0.000^{*}$ & $0.000^{*}$ & $0.000^{*}$ & $0.000 *$ & $0.000 *$ & $0.000 *$ & $0.000^{*}$ \\
\hline \multirow[t]{2}{*}{$\mathrm{MC}_{\mathrm{t}}$} & -0.034 & -0.290 & -0.474 & -0.015 & -0.148 & -0.142 & -0.291 \\
\hline & 0.949 & $0.000^{*}$ & $0.000 *$ & $0.005 *$ & $0.001 *$ & $0.009 *$ & $0.000 *$ \\
\hline \multirow[t]{2}{*}{$\mathrm{MD}_{\mathrm{t}}$} & -1.334 & 1.447 & 4.841 & -0.101 & 0.344 & -1.116 & 0.792 \\
\hline & 0.935 & 0.486 & $0.063 * * *$ & 0.547 & 0.806 & 0.499 & 0.713 \\
\hline \multirow[t]{2}{*}{$\mathrm{CC}_{\mathrm{t}}$} & -0.002 & -0.001 & 0.001 & 0.000 & -0.000 & 0.001 & -0.001 \\
\hline & 0.857 & 0.868 & 0.673 & 0.213 & 0.949 & 0.542 & 0.321 \\
\hline \multirow[t]{2}{*}{$\mathrm{CD}_{\mathrm{t}}$} & -0.009 & 0.011 & 0.026 & 0.002 & 0.022 & 0.017 & 0.033 \\
\hline & 0.939 & 0.465 & 0.178 & 0.147 & $0.036 * *$ & 0.153 & $0.041 * *$ \\
\hline \multirow[t]{2}{*}{$\mathrm{UC}_{\mathrm{t}}$} & 0.004 & -0.001 & 0.000 & -0.001 & -0.001 & -0.001 & 0.001 \\
\hline & 0.315 & 0.124 & 0.740 & 0.233 & $0.082 * * *$ & $0.002 *$ & $0.066 * * *$ \\
\hline \multirow[t]{2}{*}{$\mathrm{UD}_{\mathrm{t}}$} & -0.020 & 0.005 & 0.001 & 0.001 & 0.006 & 0.011 & 0.012 \\
\hline & 0.626 & 0.332 & 0.873 & 0.311 & 0.106 & $0.012 * *$ & $0.032 * *$ \\
\hline \multirow[t]{2}{*}{ Brent $_{t}$} & 30.265 & 5.065 & 2.111 & 0.014 & 2.028 & 3.030 & 3.090 \\
\hline & $0.000 *$ & $0.000 *$ & $0.003 *$ & 0.755 & $0.000 *$ & $0.000^{*}$ & $0.000 *$ \\
\hline \multirow[t]{2}{*}{$\mathrm{VIX}_{\mathrm{t}}$} & -10.486 & -0.617 & 0.217 & -0.169 & -0.896 & -1.601 & -0.732 \\
\hline & $0.000 *$ & $0.096^{* * *}$ & 0.636 & $0.000 *$ & $0.000 *$ & $0.000 *$ & $0.057 * * *$ \\
\hline R-Square & 0.953 & 0.973 & 0.860 & 0.921 & 0.960 & 0.977 & 0.929 \\
\hline
\end{tabular}




\begin{tabular}{lccccccc}
\hline \hline Model & $\mathbf{8}$ & $\mathbf{9}$ & $\mathbf{1 0}$ & $\mathbf{1 1}$ & $\mathbf{1 2}$ & $\mathbf{1 3}$ & $\mathbf{1 4}$ \\
\hline VIF & 8.410 & 8.410 & 8.410 & 8.410 & 8.410 & 8.410 & 8.410 \\
Durbin Watson & 0.231 & 0.187 & 0.222 & 0.205 & 0.203 & 0.213 & 0.164 \\
Cook-Weisberg & 5.100 & 6.850 & 4.510 & 8.110 & 6.840 & 7.510 & 16.900 \\
& $0.024^{* *}$ & $0.009^{*}$ & $0.034^{* *}$ & $0.004^{* *}$ & $0.009^{*}$ & $0.006^{*}$ & $0.000^{*}$ \\
\hline \hline
\end{tabular}

Notes: $* p<0.01, * * p<0.05, * * * p<0.10$

$M C_{t}$ is the number of COVID-19 cases in Malaysia at day $t ; M D_{t}$ is the number of death cases in Malaysia at day $t$; $C C_{t}$ is the number of COVID-19 cases in China at day $t ; C D_{t}$ is the number of death cases in China at day $t$; $U C_{t}$ is the number of COVID-19 cases in United States at day $t ; U D_{t}$ is the number of death cases in United States at day $t ; B R E N T_{t}$ is the Brent Crude Oil Price at day $t$; and VIX $X_{t}$ is the CBOE Volatility Index at day $t$. Model 1 refers to KLCI; Model 2 refers to Construction; Model 3 refers to Consumer; Model 4 refers to Energy; Model 5 refers to Finance; Model 6 refers to Healthcare; Model 7 refers to Industrial Product; Model 8 refers to Plantation; Model 9 refers to Property; Model 10 refers to REIT; Model 11 refers to Technology; Model 12 refers to Telecommunication; Model 13 refers to Transportation; and Model 14 refers to Utilities.

Table 5: Result of Regression Analysis (With Lagged Independent Variables)

\begin{tabular}{|c|c|c|c|c|c|c|c|}
\hline Model & $1 a$ & $2 a$ & $3 \mathbf{a}$ & $4 a$ & $5 \mathbf{a}$ & $6 a$ & $7 a$ \\
\hline \multirow{2}{*}{ Intercept } & 1444.21 & 510.36 & 120.604 & 644.312 & 14553.39 & 1093.62 & 111.31 \\
\hline & $0.000 *$ & $0.000^{*}$ & $0.000 *$ & $0.011 * *$ & $0.000 *$ & $0.000 *$ & $0.000 *$ \\
\hline \multirow[t]{2}{*}{$\mathrm{MC}_{\mathrm{t}-1}$} & -0.220 & -0.181 & -0.114 & -0.724 & -3.053 & 0.033 & -0.060 \\
\hline & $0.007 *$ & $0.064 * * *$ & $0.027 * *$ & $0.073 * * *$ & 0.135 & 0.855 & $0.049 * *$ \\
\hline \multirow[t]{2}{*}{$\mathrm{MD}_{\mathrm{t}-1}$} & 3.315 & 2.973 & 1.941 & 13.218 & 22.246 & 0.400 & 0.965 \\
\hline & 0.185 & 0.325 & 0.221 & 0.291 & 0.725 & 0.943 & 0.309 \\
\hline \multirow[t]{2}{*}{$\mathrm{CC}_{\mathrm{t}-1}$} & 0.002 & -0.101 & -0.005 & -0.048 & -0.164 & -0.006 & -0.003 \\
\hline & 0.257 & $0.000^{*}$ & $0.000^{*}$ & $0.000 *$ & $0.001 *$ & 0.163 & $0.000 *$ \\
\hline \multirow[t]{2}{*}{$\mathrm{CD}_{\mathrm{t}-1}$} & -0.231 & 0.870 & 0.430 & 3.894 & 17.414 & 0.650 & 0.274 \\
\hline & $0.003 *$ & $0.000^{*}$ & $0.000^{*}$ & $0.000 *$ & $0.000^{*}$ & $0.004 *$ & $0.000 *$ \\
\hline \multirow[t]{2}{*}{$\mathrm{UC}_{\mathrm{t}-1}$} & -0.001 & 0.002 & 0.001 & 0.008 & 0.045 & -0.002 & 0.001 \\
\hline & 0.133 & $0.005^{*}$ & $0.004 *$ & $0.006^{*}$ & $0.004 *$ & 0.124 & $0.002 *$ \\
\hline \multirow[t]{2}{*}{$\mathrm{UD}_{\mathrm{t}-1}$} & 0.004 & 0.008 & 0.003 & 0.028 & 0.079 & 0.008 & 0.002 \\
\hline & 0.486 & 0.319 & 0.429 & 0.383 & 0.623 & 0.551 & 0.440 \\
\hline \multirow[t]{2}{*}{ Brent } & 2.757 & -0.386 & 0.129 & -1.425 & -40.604 & 2.370 & 0.661 \\
\hline & $0.000 *$ & 0.645 & 0.768 & 0.681 & $0.023 * *$ & 0.129 & 0.464 \\
\hline \multirow[t]{2}{*}{ VIX } & -2.728 & -2.124 & -1.286 & -9.365 & -24.871 & -3.014 & -0.661 \\
\hline & $0.000^{*}$ & $0.000^{*}$ & $0.000 *$ & $0.000 *$ & $0.031 * *$ & $0.003^{*}$ & $0.000 *$ \\
\hline R-Square & 0.962 & 0.824 & 0.800 & 0.834 & 0.841 & 0.397 & 0.839 \\
\hline VIF & 8.410 & 8.410 & 8.740 & 8.740 & 8.740 & 8.740 & 8.740 \\
\hline Durbin Watson & 0.216 & 0.183 & 0.790 & 0.933 & 0.857 & 0.335 & 0.847 \\
\hline \multirow[t]{2}{*}{ Cook-Weisberg } & 8.570 & 7.000 & 7.420 & 9.500 & 14.010 & 3.300 & 9.900 \\
\hline & $0.003 *$ & $0.008^{*}$ & $0.007 *$ & $0.002 *$ & $0.000 *$ & $0.069^{*}$ & $0.002 *$ \\
\hline
\end{tabular}

\begin{tabular}{lccccccc}
\hline \hline Model & $\mathbf{8 a}$ & $\mathbf{9 a}$ & $\mathbf{1 0 a}$ & $\mathbf{1 1 a}$ & $\mathbf{1 2 a}$ & 13a & 14a \\
\hline Intercept & 5677.49 & 665.77 & 973.21 & 25.471 & 522.682 & 555.31 & 773.63 \\
& $0.000^{*}$ & $0.000^{*}$ & $0.000^{*}$ & $0.000^{*}$ & $0.000^{*}$ & $0.000^{*}$ & $0.000^{*}$
\end{tabular}




\begin{tabular}{|c|c|c|c|c|c|c|c|}
\hline Model & $\mathbf{8 a}$ & $9 a$ & $10 a$ & $11 \mathrm{a}$ & $12 a$ & $13 a$ & $14 a$ \\
\hline \multirow[t]{2}{*}{$\mathrm{MC}_{\mathrm{t}-1}$} & -1.893 & -0.247 & -0.116 & -0.018 & -0.226 & -0.298 & -0.176 \\
\hline & $0.065 * * *$ & 0.118 & 0.318 & $0.077 * * *$ & $0.029 * *$ & $0.033^{* *}$ & 0.228 \\
\hline \multirow[t]{2}{*}{$\mathrm{MD}_{\mathrm{t}-1}$} & 34.069 & 3.717 & 0.558 & 0.416 & 3.358 & 4.993 & 4.070 \\
\hline & 0.283 & 0.448 & 0.877 & 0.183 & 0.294 & 0.247 & 0.371 \\
\hline \multirow[t]{2}{*}{$\mathrm{CC}_{\mathrm{t}-1}$} & -0.105 & -0.015 & -0.007 & -0.001 & -0.010 & -0.014 & -0.009 \\
\hline & $0.000 *$ & $0.000 *$ & $0.008 *$ & $0.000 *$ & $0.000^{*}$ & $0.000 *$ & $0.011 * *$ \\
\hline \multirow[t]{2}{*}{$\mathrm{CD}_{\mathrm{t}-1}$} & 7.347 & 1.504 & 0.979 & 0.077 & 0.920 & 1.222 & 0.915 \\
\hline & $0.000 *$ & $0.000^{*}$ & $0.000^{*}$ & $0.000 *$ & $0.000 *$ & $0.000 *$ & $0.000 *$ \\
\hline \multirow[t]{2}{*}{$\mathrm{UC}_{\mathrm{t}-1}$} & 0.029 & 0.003 & 0.001 & 0.001 & 0.002 & 0.003 & 0.003 \\
\hline & $0.000 *$ & $0.007 *$ & 0.199 & 0.118 & $0.002 *$ & $0.004 *$ & $0.006^{*}$ \\
\hline \multirow[t]{2}{*}{$\mathrm{UD}_{\mathrm{t}-1}$} & 0.111 & 0.012 & 0.001 & 0.001 & -0.071 & 0.009 & 0.006 \\
\hline & 0.167 & 0.315 & 0.962 & 0.843 & 0.571 & 0.433 & 0.582 \\
\hline \multirow[t]{2}{*}{ Brent } & 2.459 & -2.127 & -2.047 & 0.028 & -0.071 & -0.699 & 0.729 \\
\hline & 0.780 & 0.120 & $0.043 * *$ & 0.748 & 0.936 & 0.558 & 0.564 \\
\hline \multirow[t]{2}{*}{ VIX } & -23.629 & -2.799 & 0.807 & -0.230 & -2.204 & -3.334 & -2.642 \\
\hline & $0.000 *$ & $0.002 *$ & 0.217 & $0.000 *$ & $0.000 *$ & $0.000 *$ & $0.002 *$ \\
\hline R-Square & 0.824 & 0.851 & 0.729 & 0.730 & 0.789 & 0.841 & 0.684 \\
\hline VIF & 8.740 & 8.740 & 8.740 & 8.740 & 8.740 & 8.740 & 8.740 \\
\hline Durbin Watson & 0.712 & 0.922 & 0.787 & 0.687 & 0.868 & 0.873 & 0.485 \\
\hline \multirow[t]{2}{*}{ Cook-Weisberg } & 6.500 & 13.040 & 13.150 & 16.330 & 13.870 & 11.740 & 29.980 \\
\hline & $0.011 * *$ & $0.000 *$ & $0.000 *$ & $0.000 *$ & $0.000 *$ & $0.000 *$ & $0.000 *$ \\
\hline
\end{tabular}

Notes: $* p<0.01, * * p<0.05, * * * p<0.10$

$M C_{t-1}$ is the number of COVID-19 cases in Malaysia at day $t-1 ; M D_{t-1}$ is the number of death cases in Malaysia at day $t$ 1; $C C_{t-1}$ is the number of COVID-19 cases in China at day $t-1 ; C D_{t-1}$ is the number of death cases in China at day $t-1$; $U C_{t-1}$ is the number of COVID-19 cases in United States at day $t-1 ; U D_{t-1}$ is the number of death cases in United States at day $t-1 ; B_{R E N T} T_{t-1}$ is the Brent Crude Oil Price at day $t-1$; and $V I X_{t-1}$ is the CBOE Volatility Index at day $t-1$. Model 1a refers to KLCI; Model 2a refers to Construction; Model 3a refers to Consumer; Model 4a refers to Energy; Model 5a refers to Finance; Model 6a refers to Healthcare; Model 7a refers to Industrial Product; Model 8a refers to Plantation; Model 9a refers to Property; Model 10a refers to REIT; Model 11a refers to Technology; Model 12a refers to Telecommunication; Model 13a refers to Transportation; and Model 14a refers to Utilities.

As shown in Table 5, the lagged number of COVID-19 cases in China had a significant negative relationship with the next-day performance of all sectors, except for the Healthcare sector (Model 6a) and KLCI (Model 1a). This indicated that higher COVID-19 cases in China led to a decrease in the performance of all the sectorial indices the next day, except for Healthcare sectorial index and KLCI. It is worth noting that the lagged number of deaths in China had a positive effect on all the sectors, except for KLCI. As indicated in Table 5, the number of deaths in China positively affected the performance of all the sectorial index the next day; however, that number of deaths in China negatively affected the performance of KLCI on the next day. The lagged number of COVID-19 cases in USA had a significant positive relationship with the performance of all sectors, except for the KLCI (Model 1a), Healthcare sector (Model 6a), REIT sector (Model 10a), and Technology sector (Model 11a). However, the coefficients show that the impact was extremely low and can be negligible. As indicated in Table 5, the lagged number of deaths in China positively related with the next-day performance of all sectors, except for the Telecommunication index. Consistently, the coefficients show that the impact was extremely low and can be negligible. 
The results also shown that lagged Brent Crude Oil Price had a mixed effect on all the sectorial indices and KLCI. Specifically, the Brent oil price had a significant positive relationship with the KLCI on the next day (Model 1a). However, the Brent oil price had significant negative relationship with the Finance sector (Model 5a) and REIT sector (Model 10a). The lagged VIX also had a significant negative relationship with all the sectorial indices and KLCI, except for the REIT sector (Model 10a). This indicated that the higher financial market volatility adversely affects the next-day performance of all the sectors in Malaysia, but not the REIT. Based on Tables 4 and 5, all the VIF obtained were below 10 and this indicates that there is no multicollinearity problem in the OLS regression model. However, the results of Durbin-Watson statistics and Cook-Weisberg test shown that the regression models suffered from autocorrelation and heteroscedasticity. As a remedy, this study performed the Feasible Generalized Least Square (FGLS) analysis (Montgomery, Peck, \& Vining, 2012; Vu, 2008). The results of FGLS analysis are presented in Tables 6 and 7 .

Table 6: Result of Feasible Generalized Least Square (FGLS) Analysis

\begin{tabular}{lrrrrrrr}
\hline \hline Model & \multicolumn{1}{c}{$\mathbf{1}$} & $\mathbf{2}$ & $\mathbf{3}$ & $\mathbf{4}$ & $\mathbf{5}$ & \multicolumn{1}{c}{$\mathbf{6}$} & \multicolumn{1}{c}{$\mathbf{7}$} \\
\hline Intercept & 1362.36 & 510.02 & 162.71 & 624.47 & 11958.33 & 1624.74 & 107.49 \\
& $0.000^{*}$ & $0.000^{*}$ & $0.000^{*}$ & $0.000^{*}$ & $0.000^{*}$ & $0.000^{*}$ & $0.000^{*}$ \\
$\mathrm{MC}_{\mathrm{t}}$ & -0.250 & -0.147 & -0.057 & -0.276 & -4.470 & -0.564 & -0.032 \\
& $0.003^{*}$ & $0.000^{*}$ & $0.001^{*}$ & $0.039^{* *}$ & $0.000^{*}$ & $0.001^{*}$ & $0.004^{*}$ \\
$\mathrm{MD}_{\mathrm{t}}$ & 1.332 & 1.016 & -0.312 & 0.485 & 31.027 & 1.707 & 0.152 \\
& 0.609 & 0.329 & 0.571 & 0.908 & 0.356 & 0.730 & 0.664 \\
$\mathrm{CC}_{\mathrm{t}}$ & -0.001 & 0.001 & 0.001 & 0.003 & -0.030 & 0.005 & -0.001 \\
& 0.352 & 0.751 & 0.111 & 0.222 & 0.136 & $0.074^{* * *}$ & 0.456 \\
$\mathrm{CD}_{\mathrm{t}}$ & 0.017 & 0.013 & 0.006 & 0.031 & 0.092 & 0.046 & 0.006 \\
& 0.382 & $0.099 * * *$ & 0.135 & 0.310 & 0.709 & 0.210 & $0.025^{* *}$ \\
$\mathrm{UC}_{\mathrm{t}}$ & -0.001 & -0.001 & -0.001 & -0.002 & -0.008 & 0.000 & 0.001 \\
& 0.684 & 0.220 & 0.098 & 0.119 & 0.344 & 0.984 & $0.003^{*}$ \\
$\mathrm{UD}_{\mathrm{t}}$ & 0.003 & 0.003 & 0.002 & 0.003 & -0.002 & 0.017 & 0.002 \\
& 0.595 & 0.278 & 0.129 & 0.758 & 0.981 & 0.165 & $0.027^{* *}$ \\
Brent $_{\mathrm{H}}$ & 3.807 & 2.349 & 0.871 & 10.672 & 55.023 & -4.256 & 0.766 \\
& $0.000^{*}$ & $0.000^{*}$ & $0.000^{*}$ & $0.000^{*}$ & $0.000^{*}$ & $0.002^{*}$ & $0.000^{*}$ \\
$\mathrm{VIX}_{\mathrm{t}}$ & -1.881 & -0.875 & -0.618 & -3.843 & -11.559 & -2.895 & -0.301 \\
& $0.000^{*}$ & $0.000^{*}$ & $0.000^{*}$ & $0.000^{*}$ & $0.052^{* * *}$ & $0.001 *$ & $0.000^{*}$ \\
\hline \hline
\end{tabular}

\begin{tabular}{lrrrrrrr}
\hline \hline Model & \multicolumn{1}{c}{$\mathbf{8}$} & \multicolumn{1}{c}{$\mathbf{9}$} & \multicolumn{1}{c}{$\mathbf{1 0}$} & \multicolumn{1}{c}{$\mathbf{1 1}$} & \multicolumn{1}{c}{$\mathbf{1 2}$} & \multicolumn{1}{c}{$\mathbf{1 3}$} & \multicolumn{1}{c}{$\mathbf{1 4}$} \\
\hline Intercept & 5720.466 & 494.864 & 836.634 & 41.752 & 558.430 & 584.050 & 809.318 \\
& $0.000^{*}$ & $0.000^{*}$ & $0.000^{*}$ & $0.000^{*}$ & $0.000^{*}$ & $0.000^{*}$ & $0.000^{*}$ \\
$\mathrm{MC}_{\mathrm{t}}$ & -0.034 & -0.290 & -0.474 & -0.015 & -0.148 & -0.142 & -0.291 \\
& 0.947 & $0.000^{*}$ & $0.000^{*}$ & $0.002^{*}$ & $0.001^{*}$ & $0.005^{*}$ & $0.000^{*}$ \\
$\mathrm{MD}_{\mathrm{t}}$ & -1.334 & 1.447 & 4.841 & -0.101 & 0.344 & -1.116 & 0.792 \\
& 0.932 & 0.466 & $0.050^{* * *}$ & 0.529 & 0.797 & 0.479 & 0.700 \\
$\mathrm{CC}_{\mathrm{t}}$ & -0.002 & -0.001 & 0.001 & 0.000 & -0.000 & 0.001 & -0.001 \\
& 0.851 & 0.862 & 0.658 & 0.191 & 0.947 & 0.523 & 0.298 \\
$\mathrm{CD}_{\mathrm{t}}$ & -0.009 & 0.011 & 0.026 & 0.002 & 0.022 & 0.017 & 0.033 \\
& 0.936 & 0.444 & 0.156 & 0.127 & $0.026^{* *}$ & 0.133 & $0.031^{* *}$
\end{tabular}




\begin{tabular}{lrrrrrrr}
\hline \hline Model & $\mathbf{8}$ & $\mathbf{9}$ & $\mathbf{1 0}$ & $\mathbf{1 1}$ & $\mathbf{1 2}$ & \multicolumn{1}{c}{$\mathbf{1 3}$} & \multicolumn{1}{c}{$\mathbf{1 4}$} \\
\hline UC $_{\mathrm{t}}$ & 0.004 & -0.001 & 0.000 & -0.001 & -0.001 & -0.001 & 0.001 \\
& 0.292 & 0.105 & 0.728 & 0.210 & $0.067^{* * *}$ & $0.001^{*}$ & $0.053^{* * *}$ \\
UD $_{\mathrm{t}}$ & -0.020 & 0.005 & 0.001 & 0.001 & 0.006 & 0.011 & 0.012 \\
& 0.609 & 0.309 & 0.867 & 0.288 & $0.089 * * *$ & $0.007^{* *}$ & $0.023^{* *}$ \\
Brent & 30.265 & 5.065 & 2.111 & 0.014 & 2.028 & 3.030 & 3.090 \\
& $0.000^{*}$ & $0.000^{*}$ & $0.002^{*}$ & 0.744 & $0.000^{*}$ & $0.000^{*}$ & $0.000^{*}$ \\
VIX & -10.486 & -0.617 & 0.217 & -0.169 & -0.896 & -1.601 & -0.732 \\
& $0.000^{*}$ & $0.079^{* * *}$ & 0.620 & $0.000^{*}$ & $0.000^{*}$ & $0.000^{*}$ & $0.045^{* *}$ \\
\hline \hline
\end{tabular}

Notes: $* p<0.01, * * p<0.05, * * * p<0.10$

$M C_{t}$ is the number of COVID-19 cases in Malaysia at day $t ; M D_{t}$ is the number of death cases in Malaysia at day $t ; C C_{t}$ is the number of COVID-19 cases in China at day $t ; C D_{t}$ is the number of death cases in China at day $t: U C_{t}$ is the number of COVID-19 cases in United States at day $t ; U D_{t}$ is the number of death cases in United States at day $t ; B R E N T_{t}$ is the Brent Crude Oil Price at day $t$; and VIX $X_{t}$ is the CBOE Volatility Index at day $t$. Model 1 refers to KLCI; Model 2 refers to Construction; Model 3 refers to Consumer; Model 4 refers to Energy; Model 5 refers to Finance; Model 6 refers to Healthcare; Model 7 refers to Industrial Product; Model 8 refers to Plantation; Model 9 refers to Property; Model 10 refers to REIT; Model 11 refers to Technology; Model 12 refers to Telecommunication; Model 13 refers to Transportation; and Model 14 refers to Utilities.

Table 7: Result of Feasible Generalized Least Square (FGLS) Analysis

\begin{tabular}{|c|c|c|c|c|c|c|c|}
\hline Model & $1 \mathbf{a}$ & $2 a$ & $\mathbf{3 a}$ & $4 a$ & $5 \mathbf{a}$ & $6 a$ & $7 \mathbf{a}$ \\
\hline \multirow{2}{*}{ Intercept } & 1444.21 & 510.36 & 120.604 & 644.312 & 14553.39 & 1093.62 & 111.31 \\
\hline & $0.000 *$ & $0.000^{*}$ & $0.000 *$ & $0.007^{*}$ & $0.000^{*}$ & $0.000^{*}$ & $0.000 *$ \\
\hline \multirow[t]{2}{*}{$\mathrm{MC}_{\mathrm{t}-1}$} & -0.220 & -0.181 & -0.114 & -0.724 & -3.053 & 0.033 & -0.060 \\
\hline & $0.004 *$ & $0.050 * * *$ & $0.019 * *$ & $0.059 * * *$ & 0.116 & 0.848 & $0.038 * *$ \\
\hline \multirow[t]{2}{*}{$\mathrm{MD}_{\mathrm{t}-1}$} & 3.315 & 2.973 & 1.941 & 13.218 & 22.246 & 0.400 & 0.965 \\
\hline & 0.164 & 0.302 & 0.198 & 0.268 & 0.713 & 0.940 & 0.286 \\
\hline \multirow[t]{2}{*}{$\mathrm{CC}_{\mathrm{t}-1}$} & 0.002 & -0.101 & -0.005 & -0.048 & -0.164 & -0.006 & -0.003 \\
\hline & 0.233 & $0.000 *$ & $0.000 *$ & $0.000 *$ & $0.000 *$ & 0.142 & $0.000 *$ \\
\hline \multirow[t]{2}{*}{$\mathrm{CD}_{\mathrm{t}-1}$} & -0.231 & 0.870 & 0.430 & 3.894 & 17.414 & 0.650 & 0.274 \\
\hline & $0.001 *$ & $0.000 *$ & $0.000 *$ & $0.000 *$ & $0.000 *$ & $0.004^{*}$ & $0.000 *$ \\
\hline \multirow[t]{2}{*}{$\mathrm{UC}_{\mathrm{t}-1}$} & -0.001 & 0.002 & 0.001 & 0.008 & 0.045 & -0.002 & 0.001 \\
\hline & 0.114 & $0.002 *$ & $0.002 *$ & $0.004 *$ & $0.002 *$ & 0.105 & $0.001 *$ \\
\hline \multirow[t]{2}{*}{$\mathrm{UD}_{\mathrm{t}-1}$} & 0.004 & 0.008 & 0.003 & 0.028 & 0.079 & 0.008 & 0.002 \\
\hline & 0.466 & 0.296 & 0.407 & 0.360 & 0.607 & 0.532 & 0.418 \\
\hline \multirow[t]{2}{*}{ Brent } & 2.757 & -0.386 & 0.129 & -1.425 & -40.604 & 2.370 & 0.661 \\
\hline & $0.000^{*}$ & 0.630 & 0.758 & 0.667 & $0.015^{* *}$ & 0.110 & 0.443 \\
\hline \multirow[t]{2}{*}{ VIX } & -2.728 & -2.124 & -1.286 & -9.365 & -24.871 & -3.014 & -0.661 \\
\hline & $0.000 *$ & $0.000 *$ & $0.000 *$ & $0.000 *$ & $0.023 * *$ & $0.002 *$ & $0.000^{*}$ \\
\hline Model & $\mathbf{8 a}$ & $9 a$ & $10 a$ & $11 \mathrm{a}$ & $12 \mathrm{a}$ & 13a & $14 a$ \\
\hline \multirow[t]{2}{*}{ Intercept } & 5677.49 & 665.77 & 973.21 & 25.471 & 522.682 & 555.31 & 773.63 \\
\hline & $0.000 *$ & $0.000 *$ & $0.000 *$ & $0.000^{*}$ & $0.000 *$ & $0.000^{*}$ & $0.000^{*}$ \\
\hline \multirow[t]{2}{*}{$\mathrm{MC}_{\mathrm{t}-1}$} & -1.893 & -0.247 & -0.116 & -0.018 & -0.226 & -0.298 & -0.176 \\
\hline & $0.051 * * *$ & 0.100 & 0.295 & $0.062 * * *$ & $0.021 * *$ & $0.024 * *$ & 0.205 \\
\hline
\end{tabular}




\begin{tabular}{lccccccc}
\hline \hline Model & $\mathbf{8 a}$ & $\mathbf{9 a}$ & $\mathbf{1 0 a}$ & $\mathbf{1 1 a}$ & $\mathbf{1 2 a}$ & $\mathbf{1 3 a}$ & $\mathbf{1 4 a}$ \\
\hline $\mathrm{MD}_{\mathrm{t}-1}$ & 34.069 & 3.717 & 0.558 & 0.416 & 3.358 & 4.993 & 4.070 \\
& 0.260 & 0.426 & 0.871 & 0.161 & 0.271 & 0.224 & 0.348 \\
$\mathrm{CC}$ & -0.105 & -0.015 & -0.007 & -0.001 & -0.010 & -0.014 & -0.009 \\
& $0.000^{*}-1$ & $0.000^{*}$ & $0.005^{*}$ & $0.000^{*}$ & $0.000^{*}$ & $0.000^{*}$ & $0.007^{*}$ \\
& 7.347 & 1.504 & 0.979 & 0.077 & 0.920 & 1.222 & 0.915 \\
$\mathrm{CD}_{\mathrm{t}-1}$ & $0.000^{*}$ & $0.000^{*}$ & $0.000^{*}$ & $0.000^{*}$ & $0.000^{*}$ & $0.000^{*}$ & $0.000^{*}$ \\
& 0.029 & 0.003 & 0.001 & 0.001 & 0.002 & 0.003 & 0.003 \\
$\mathrm{UC}_{\mathrm{t}-1}$ & $0.000^{*}$ & $0.004^{*}$ & 0.177 & $0.099^{* *}$ & $0.001^{*}$ & $0.002^{*}$ & $0.003^{*}$ \\
& 0.111 & 0.012 & 0.001 & 0.001 & -0.071 & 0.009 & 0.006 \\
$\mathrm{UD}_{\mathrm{t}-1}$ & 0.146 & 0.292 & 0.960 & 0.835 & 0.552 & 0.411 & 0.564 \\
& 2.459 & -2.127 & -2.047 & 0.028 & -0.071 & -0.699 & 0.729 \\
$\mathrm{Brent}$ & 0.770 & 0.101 & $0.032^{* *}$ & 0.736 & 0.933 & 0.539 & 0.545 \\
& -23.629 & -2.799 & 0.807 & -0.230 & -2.204 & -3.334 & -2.642 \\
$\mathrm{VIX}$ & $0.000^{*}$ & $0.001^{*}$ & 0.194 & $0.000^{*}$ & $0.000^{*}$ & $0.000^{*}$ & $0.001^{*}$ \\
\hline \hline
\end{tabular}

Notes: $* p<0.01, * * p<0.05, * * * p<0.10$

$M C_{t-1}$ is the number of COVID-19 cases in Malaysia at day $t-1 ; M D_{t-1}$ is the number of death cases in Malaysia at day $t$ $1 ; C C_{t-1}$ is the number of COVID-19 cases in China at day $t-1 ; C D_{t-1}$ is the number of death cases in China at day $t-1$; $U C_{t-1}$ is the number of COVID-19 cases in United States at day $t-1 ; U D_{t-1}$ is the number of death cases in United States at day $t-1 ; B_{R E N T_{t-1}}$ is the Brent Crude Oil Price at day $t-1$; and $V I X_{t-1}$ is the CBOE Volatility Index at day $t-1$. Model 1a refers to KLCI; Model 2a refers to Construction; Model 3a refers to Consumer; Model 4a refers to Energy; Model 5a refers to Finance; Model 6a refers to Healthcare; Model 7a refers to Industrial Product; Model 8a refers to Plantation; Model 9a refers to Property; Model 10a refers to REIT; Model 11a refers to Technology; Model 12a refers to Telecommunication; Model 13a refers to Transportation; and Model 14a refers to Utilities.

Based on Tables 6 and 7, the coefficients of independent variables obtained under FGLS analysis were similar to the ones obtained under OLS analysis. Meanwhile, the results of FGLS show that the $p$-values for all the independent variables slightly adjusted for the model. The independent variables that significantly affected the sectorial indices and KLCI remain significant under the FGLS analysis. The number of COVID-19 cases in Malaysia remains significant and negatively related with the performance of sectorial indices and KLCI, except for the Plantation sector. In addition, the results of FGLS (Table 6) show that the number of deaths in China were positively related with performance of Construction index (Model 2) at the significance level of 10\%. Table 6 also shows that the number of death cases in USA is positively related with performance of the Telecommunication index (Model 12) at the significance level of $10 \%$. As for the lagged independent variables, the results obtained under OLS are similar to the ones obtained from FGLS. There is only a slight adjustment in the p-value of the independent variables.

As a summary, the number of COVID-19 cases are consistently shown to have a significant negative impact on the Malaysian sectorial indices and KLCI, but not the Plantation sector. This suggests that the Plantation sector was a defensive sector to invest in during this critical period. In addition, the number of deaths in China tended to have a mixed effect on certain sectors in the Malaysian stock market. As an oil exporting country, the majority of the sectors in the Malaysian stock market were found to be positively related with the movement of the Brent Crude Oil Price. Finally, the empirical results of this study also show that higher financial market volatility tended to affect the performance of all the indices, except for REIT index. To some extent, the performance of the REIT sector may face a great challenge in the coming financial quarters due to the Movement 
Control Order (MCO), which limits the movement of 32 million Malaysians and retail business activities for nearly two months.

\section{CONCLUSION}

This study contributes to finance literature by investigating the impacts of the COVID-19 outbreak on the performance of the Malaysian stock market by using daily data covering $31^{\text {st }}$ December 2019 to 18 April 2020. This study carried out regression analysis by including the Kuala Lumpur Composite Index (KLCI) and 13 sectorial indices as the dependent variables. Meanwhile, the proxies of COVID-19 outbreak - Brent Crude Oil Price and financial market volatility (VIX) were used as the independent variables. The results of the regression analysis revealed that the number of COVID-19 cases significantly affected the performance of almost all sectors in Malaysian stock market. This study also recommends that investors monitor changes in the number of COVID-19 cases in Malaysia before making any investment decision regarding the Malaysian stock market. On the other hand, the number of COVID-19 cases in China and USA showed significant impacts on the performance of only a few sectors. Interestingly, the number of deaths in China showed a lagged and mixed effect on the Malaysian stock market. Furthermore, the Malaysian stock market was also found to be significantly affected by the Brent Crude Oil Price and the financial market volatility index. These are the two external factors that investors should consider during the COVID-19 outbreak period because Malaysia is an oil-exporting country. This study helps investors in identifying the significant factors to consider before making any investment decision in particular sectors during the COVID-19 outbreak period. The findings of this study also underscore the importance of monitoring not only the number of COVID-19 cases, but also the external factors. For further research, researchers can further the analysis by using a longer sample period and exploring more proxies for the COVID-19 outbreak.

\section{ACKNOWLEDGEMENT}

Financial support from University Malaysia Sarawak and Digital Sarawak CoE [UHSB/BAM2018/083] are gratefully acknowledged. All remaining flaws are the responsibilities of the authors.

\section{REFERENCE}

Albulescu, C. T. (2020). Coronavirus and financial volatility: 40 days of fasting and fear. Cornell University. Retrieved from https://arxiv.org/abs/2003.04005

Aravind, M., \& Manojkrishnan, C. G. (2020). COVID-19: Effect on leading pharmaceutical stocks listed with NSE. International Journal of Research in Pharmaceutical Sciences, 11(1), 31-36.

Azman, N. H. (2020). COVID-19 could cost Malaysia's economy RM5.9b this year. The Malaysian Reverse. Retrieved from https://themalaysianreserve.com/2020/02/24/covid19-could-cost-malaysias-economy-rm5-9b-this-year/

Beutels, P., Jia, N., Zhou, Q. Y., Smith, R., Cao, W. C., \& Vias, S. J. (2009). The economic impact of SARS in Beijing, China. Tropical Medicine and International Health, 14(1), 85-91. 
Chen, C. D., Chen, C. C., Tang, W. W., \& Huang, B. Y. (2009). The positive and negative impacts of the SARS outbreak: A case of the Taiwan industries. Journal of Developing Areas, 43(1), 281-293.

Chen, M. P., Lee, C. C., Lin, Y. H., \& Chen, W. Y. (2018). Did the SARS epidemic weaken the integration of Asian stock markets? Evidence from smooth time-varying cointegration analysis. Economic Research, 31(1), 908-926.

Durbin, J., \& Watson, G. S. (1971). Testing for serial correlation in least square regression III. Biometrika, 58(1), 1-19.

Estrada, M. A. R., Park, D. H., \& Lee, M. S. (2020). The evaluation of the final impact of Wuhan COVID-19 on trade, tourism, transport, and electricity consumption of China. Retrieved from https://ssrn.com/abstract=3551093

Hai, W., Zhao, Z., Wang, J., \& Hou, Z. G. (2004). The short term impacts of SARS on the Chinese economy. Asian Economic Papers, 3(1), 57-61.

Hamid, A. B. A. (2020). The effects of Coronavirus (COVID-19) in the tourism industy in China. Asian Journal of Multidisciplinary Studies, 3(1), 1-7.

International Air Transport Association (IATA) (2020). COVID-19 puts over half of 2020 passenger revenues at risk. Retrieved from https://www.iata.org/en/pressroom/pr/202004-14-01/

Khan, D., \& Khan, L. Y. (2020). The economic impact of COVID-19 on developing countries. Inter Press Service News Agency. Retrieved from http://www.ipsnews.net/2020/04/theeconomic-impact-of-covid-19-on-developing-countries/

Li, R., Zhang, R., Zhang, M., \& Zhang, Q. (2020). Investment analysis and strategy for Covid-19. Retrieved from https://ssrn.com/abstract $=3563300$

Liu, Y., Gayle, A. A., Wilder-Smith, A., \& Rocklov, J. (2020). The reproductive number of COVID-19 is higher compared to SARS coronavirus. Journal of Travel Medicine, 27(2), $1-4$.

Liu, H. Y., Manzoor. A., Wang, C. Y., Zhang, L., \& Manzoor, Z. (2020). The COVID-19 outbreak and affected countries stock market response. International Journal of Environmental Research and Public Health, 17(8), 1-19.

Malaysia Association of Hotel. (2020). Tourism Comes to a Standstill. Retrieved from http://www.hotels.org.my/press/22578-tourism-comes-to-a-standstill

Montgomery, D. C., Peck, E. A., \& Vining, G. G. (2012). Introduction to Linear Regression Analysis. Canada: John Wiley \& Sons.

Nia, V. M. (2020). The effect of Corona outbreak on the Indonesian stock market. American Journal of Humanities and Social Sciences Research, 4(3), 358-370.

OECD (2020). Coronavirus: The world economy as risk. Retrieved from https:/www.oecd.org/berlin/publikationen/Interim-Economic-Assessment-2-March2020.pdf

Ozili, P. K. (2020). COVID-19 pandemic and economic crisis: The Nigerian experience and structural causes. Retrieved from https://ssrn.com/abstract=3567419

Qiu, W., Chu, C., Mao, A., \& Wu, J. (2018). The impacts on health, society, and economy of SARS and H7N9 outbreaks in China: A case comparison study. Hindawi. Retrieved from https://www.hindawi.com/journals/jeph/2018/2710185/

Rani, R. (2020). The impact of Corona Virus on Indian Economy. Studies in Indian Place Names, 40(60), 3618-3626.

Sansa, N. A. (2020). The impact of the COVID-19 on the financial markets: Evidence from China and USA. Electronic Research Journal of Social Science and Humanities, 2(1), 29-39. 
Siu, A., \& Wong, Y. C. R. (2004). Economic impact of SARS: The case of Hong Kong. Asian Economic Papers, 3(1), 62-83.

Smith, R. D. (2006). Responding to global infectious disease outbreaks: Lessons from SARS on the role of risk perception, communication and management. Social Science and Medicine, 63(12), 3113-3123.

Star Media (2020). Short position: Cluesless on MCO impact. Retrieved from https://www.thestar.com.my/business/business-news/2020/03/21/short-positionclueless-on-mco-impact

Tashanova, D., Sekerbay, A., Chen, D., Luo, Y., Zhao, S., \& Zhang, Q. (2020). Investment opportunities and strategies in an Era of Coronavirus Pandemic. Retrieved from https://ssrn.com/abstract $=3567445$

Toda, A. A. (2020). Susceptible-Infected-Recovered (SIR) dynamics of COVID-19 and economic impact. Cornell University. Retrieved from https://arxiv.org/pdf/2003.11221.pdf

$\mathrm{Vu}$, T. B. (2008). Foreign direct investment and endogenous growth in Vietnam. Applied Economics, 40(9), 1165-1173.

Wang, M. D., \& Jolly, A. M. (2004). Changing virulence of the SARS virus: The epidemiological evidence. Bullentin of the World Heath Organization, 82(7), 547-549.

Watanabe, T. (2020). The response of consumption and prices in Japan to the COVID-19 crisis and the Tohoku earthquake. JSPS Grant-in-Aid for Scientific Research Working Paper. No 020, 1-16.

Wong, G. (2008). Has SARS infected the property market? Evidence from Hong Kong. Journal of Urban Economcis, 63(1), 74-95.

Worldometer (2020). Coronavirus. Retrieved from https://www.worldometers.info/coronavirus/

Yan, H., Andy, T., Logan. S., Zhang, Q. (2020). Analysis of the effect of COVID-19 on the stock market and potential investing strategies. Retrieved from https://ssrn.com/abstract=3563380

Yilmazkuday, H. (2020). COVID-19 Effects on the S\&P 500 Index. Retrieved from https://ssrn.com/abstract $=3555433$

Zeren, F., \& Hizarci, A. E. (2020). The impact of COVID-19 coronavirus on stock markets: Evidence from selected countries. Muhasebe ve Finans Incelemeleri Dergisi, 3(1), 78-84.

Zhou, L., Wu, K., Liu, H., Gao, Y., \& Gao, X. (2020). CIRD-F: Spread and influence of COVID19 in China. Journal of Shanghai Jiao Tong University, 25(2), 147-156. 